University of Wollongong

Research Online

Faculty of Engineering and Information

Faculty of Engineering and Information

Sciences - Papers: Part B

Sciences

2018

Load forecasting under changing climatic conditions for the city of Sydney, Australia

Tanvir Ahmed

University of Wollongong, ta539@uow.edu.au

Dao Hoang $\mathrm{Vu}$

University of Wollongong, dhv972@uowmail.edu.au

Kashem M. Muttaqi

University of Wollongong, kashem@uow.edu.au

Ashish P. Agalgaonkar

University of Wollongong, ashish@uow.edu.au

Follow this and additional works at: https://ro.uow.edu.au/eispapers1

Part of the Engineering Commons, and the Science and Technology Studies Commons

Research Online is the open access institutional repository for the University of Wollongong. For further information contact the UOW Library: research-pubs@uow.edu.au 


\title{
Load forecasting under changing climatic conditions for the city of Sydney, Australia
}

\author{
Abstract \\ In the current context, climate change has become an unequivocal phenomenon. Although it primarily \\ encompasses change in temperature, nevertheless other weather variables such as rainfall, wind speed, \\ evaporation and humidity can also be affected as a result of climate change. Addressing the impacts of \\ climate change on electricity demand is essential for predicting the future demand. For example, cooling \\ and heating requirements change significantly with respect to climate change that may result to the \\ change in electricity load demand. In this paper, a backward elimination based multiple regression \\ approach is proposed for analyzing the influence of climatic variables on load forecasting. A correlation \\ analysis has been carried out using Pearson's correlation coefficient to examine the interdependency \\ between different climatic variables in the context of Sydney, one of the most densely populated cities in \\ Australia. Regression based analysis has been performed to examine the relationship between per capita \\ electricity demand and associated climatic variables. 'Degree Days' concept has been utilized to \\ determine balance point temperature. Backward elimination based multiple regression is used to exclude \\ non-significant climatic variables and evaluate the sensitivity of significant variables related to the load \\ demand. Average change in future per capita electricity demand has been predicted using the proposed \\ approach for the city of Sydney, Australia. Results indicate that the demand for Sydney will increase by $6 \%$ \\ by 2030 .

\section{Disciplines} \\ Engineering | Science and Technology Studies

\section{Publication Details} \\ T. Ahmed, D. H. Vu, K. M. Muttaqi \& A. P. Agalgaonkar, "Load forecasting under changing climatic \\ conditions for the city of Sydney, Australia," Energy, vol. 142, pp. 911-919, 2018.
}

This journal article is available at Research Online: https://ro.uow.edu.au/eispapers1/744 


\title{
Load Forecasting under Changing Climatic Conditions for the City of Sydney, Australia
}

\author{
T. Ahmed, D. H. Vu, K. M. Muttaqi and A. P. Agalgaonkar \\ Australian Power Quality and Reliability Centre \\ School of Electrical, Computer and Telecommunications Engineering \\ University of Wollongong, New South Wales, Australia \\ Email: ashish@uow.edu.au
}

\begin{abstract}
In the current context, climate change has become an unequivocal phenomenon. Although it primarily encompasses change in temperature, other weather variables such as rainfall, wind speed, evaporation and humidity can also be affected as a result of climate change. Addressing the impacts of climate change on electricity demand is essential for predicting the future demand as cooling and heating requirements change significantly with respect to climate change. In this paper, a backward elimination based multiple regression approach is proposed for analyzing the influence of climatic variables on load forecasting. A correlation analysis has been carried out using Pearson's correlation coefficient to examine the interdependency between different climatic variables in the context of Sydney, Australia. Regression based analysis has been performed to examine the relationship between per capita demand and associated climatic variables. 'Degree Days' concept has been utilized to determine balance point temperature. Backward elimination based multiple regression is used to exclude non-significant climatic variables and evaluate the sensitivity of significant variables related to the load demand. Average change in future per capita demand has been predicted using the proposed approach for the city of Sydney, Australia. Results indicate that the demand for Sydney will increase by $6 \%$ by 2030.
\end{abstract}

Keywords

Climate change; electricity demand forecasting; power system planning; regression analysis; weather variables.

\section{Introduction}

Population all over the world is continually increasing, which demands for more electricity generation to satisfy the individual needs [1]. Also, with the advent of new technologies and improved life-style, average use of electrical equipment is also increasing gradually. Consequently, power industries need to undertake effective system expansion planning to cater additional load demand. On the other hand, power industries are marked as the biggest emitter of green-house gases [2] since ongoing demand growth requires more fossil fuel to be burned, thereby aggravating the emission problem. Therefore, climate change has emerged as an additional concern for the policy makers in recent years and revealing the influence of climate change on electricity demand is significantly important in developing the future electrical power systems.

Studies reported in the literature highlight the fact that there is a significant impact of climate change on electricity demand. Sailor [3] has applied multiple regression model to examine the effect of temperature on load demand, especially in several US States and reported that the demands in some States have positive sensitivity toward temperature while demands in other States have negative sensitivity. Howden and Crimp [4] have carried out a study for four Australian conurbations: Sydney, Melbourne, Brisbane and Adelaide in 2001 and found that the $7{ }^{\circ} \mathrm{C}$ rise in temperature may cause $1.5 \%$ yearly average demand growth in Sydney and Melbourne, and $10 \%$ to $28 \%$ growth in yearly average demands of Brisbane and Adelaide. The iterative regression analysis approach has been used in their study to find balance point temperature. The development of a model for reproducing load duration curves for four different Australian states, which are part of Australian national electricity market, considering climate change effects is detailed in [5]. In [6], it is reported that the impact of climate change is quite different in the neighboring country, New Zealand, where $1^{\circ} \mathrm{C}$ rise in temperature will result into $1.4 \%$ drop in yearly average electricity demand; however $1{ }^{\circ} \mathrm{C}$ decrement in temperature will result into $1.6 \%$ increase in average yearly electricity demand. Study conducted by Amato et al. [7] has found that there will be $2.1 \%$ increase in per capita electricity demand by 2020 relative to a baseline climate projection. Wilson et al. [8] have estimated that a $1.5^{\circ} \mathrm{C}$ increase in temperature would increase total net expenditure by $4 \%$ for the state of California by the year 2100 due to increased cooling and decreased heating demand. Similarly, a $5^{\circ} \mathrm{C}$ increase in temperature would increase the above expenditures by $22 \%$. Authors of [9] have reported that temperature alone may not be sufficient to 
AEMO: Australian energy market operator

BOM: Bureau of meteorology

CSIRO: Commonwealth scientific and industrial research organisation

IPCC: Intergovernmental panel on climate change

A1, A2, B1, B2, A1F1 (families): different scenarios in IPCC

NSW: New South Wales

PDF: Probability distribution function

SRES: Special report on emission scenario

CDD: Cooling degree days

HDD: Heating degree days

$T_{b}$ : balance point temperature

$u$ : the unit function

$T:$ the temperature

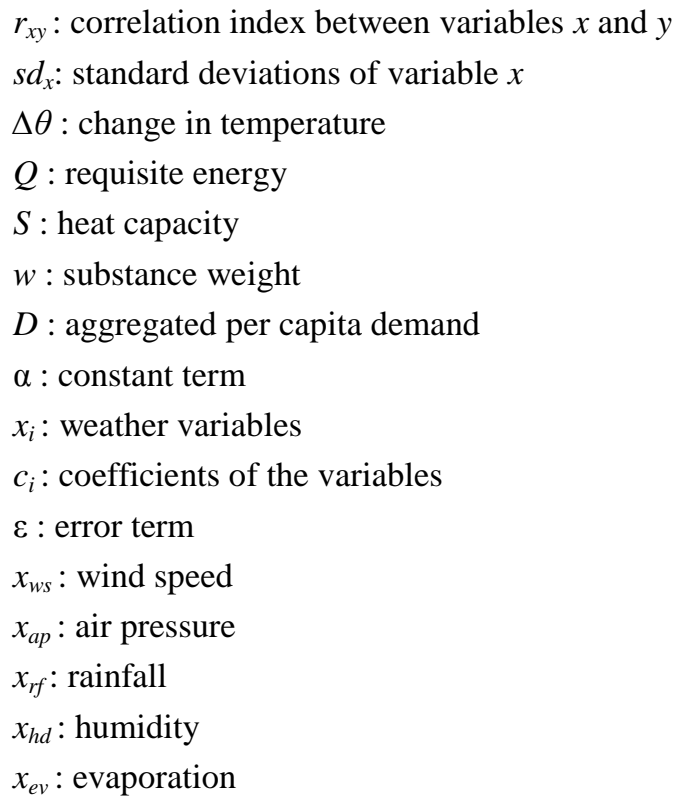

determine the impact of climate change on electricity demand and considered the effect of other variables in the proposed study. Also, the necessity of incorporating socio-economic dynamics in estimating future energy demand is highlighted in [10].

Recently, numerous research studies have been conducted to analyze the impact of the climate change on electricity consumption. In [11], based on different scenarios, the authors have conducted an investigation about the impacts of climate change on the electricity consumption in California. In [12], the impact of climate change on peak demand and total energy consumption is studied in detail for whole America. The effect of climate change is also studied for Mediterranean Europe in [13]. The climatic impacts on demand can be represented by the mean daily air temperature as in [14]. In [15] and [16], it has been illustrated that the per capita demand in state of NSW, Australia predominantly depends on the climatic variables such as temperature, wind speed, evaporation, and humidity.

In the literature, demand forecasting can be formulated based on historical data using Box-Jenkin models. Authors in [17] employed an autoregressive moving average (ARMA) model to forecast electricity demand because the model can capture both non-seasonal and seasonal cycles of the load data. To enhance the forecasting performance, various techniques can be used to decompose the demand data before building the forecasting model [18]. The decomposition helps in improving the forecasting performance significantly. For example, it is noted in [19] that the wavelet technique, which was used to decompose electricity demand into independent orthogonal components, contribute significantly to the improvement of forecasting model. However, solely employing historical data in forecasting model is not sufficient since the exogenous variables have been reported to have significant impacts on electricity demand.

Since the electricity demand is strongly influenced by climate change, examining the impacts of weather variation in different scenarios may help to develop the robust forecasting for the future electricity consumption. This paper proposes a novel contribution by investigating the dependency of electricity demand on various climatic variables and predicting the future change in average per capita demand for Sydney, Australia based on future climate projections. The investigation process has been carried out using a regression analysis in conjunction with a Pearson correlation analysis. In these analyses, balance point temperature for Sydney has been calculated using the relationship between historical temperature and corresponding electricity demand. Also, the proposed study includes several weather variables in the regression analysis and investigates their influence on the electricity demand. The per capita demand has been used instead of total demand to dispose the influence of population growth. Finally, changes of demand are forecasted based on different scenarios from future climate projections which have been proposed by the Commonwealth Scientific and Industrial Research Organisation (CSIRO), Australia.

The main contributions of this paper are as follows.

- A correlation analysis has been carried out to estimate the correlation between temperature and other weather variables. Also, using the historical data and a Pearson's correlation, a correlation matrix has been generated. This provides useful information to assess the impacts of relevant weather variables on electricity demand.

- A novel conceptual framework involving correlation analysis is adopted to apply multiple regression analysis and determine strong influence of significant weather variables on the electricity load demand. The future load demand has been predicted for the city of Sydney, Australia considering the impacts of environmental variables, derived based on the 
CSIRO projections on the climate data, and their degree of sensitivity with respect to the changing demand.

- The obtained results show that the change in future Cooling Degree Days (CDD) due to temperature variation, wind speed and evaporation affect the future load demand while Heating Degree Days (HDD), rainfall and humidity exhibit negligible effect on the future demand.

The rest of the paper have been structured as follows: Section II discusses the global climate change and emission scenarios, and Section III highlights climate change in the Australian context. In Section IV, a multiple regression model is developed to evaluate the demand sensitivity to weather variables and forecast electricity demand in the future. Results and associated discussions have been presented in Section V, followed by conclusion in Section VI.

\section{Global Climate Change and Emission Scenarios}

Intergovernmental Panel on Climate Change (IPCC) has defined climate change as "a change in the state of the climate that can be identified (e.g. using statistical tests) by changes in the mean and/or the variability of its properties, and that persists for an extended period, typically decades or longer" [2]. According to the IPCC report, average temperature all over the globe has increased by $0.13^{\circ} \mathrm{C}$ per decade. It is also reported that climate is changing more rapidly in recent times than any other time in the history. Temperature is one of the most influential climatic variables, which has significant impact on electricity demand. However, other weather variables such as rainfall, humidity and wind speed might also play a dominant role. It is noted that the variations in electricity demand with respect to changes in weather variables are region specific and exhibit vast diversity around the world. The effect of changing climatic conditions on the above listed weather variables is more severe in certain regions as compared to other regions [20].

IPCC has developed a set of long term emission scenarios that helps to analyze influence of various driving forces such as temperature, humidity, rainfall etc. on future emission outcomes. In [2], four different narrative storylines described by IPCC depict the relationship between the driving forces, affecting total emissions, and their evolution. Each storyline represents different demographic, social, economic, technological and environmental development. A1 storyline describes a future world of very rapid economic growth, global population that peaks in mid-century and declines thereafter, and the rapid introduction of new and more efficient technologies. A2 storyline illustrates a heterogeneous world while B1 storyline focuses on a convergent world with the same global population that peaks in mid-century and declines thereafter, as in the A1 storyline [21]. B1 storyline also describes rapid changes in economic structure mainly towards a service and information economy, with reduction in material intensity and the introduction of clean and resource-efficient technologies. B2 storyline describes a world in which the emphasis is on local solutions to economic, social and environmental sustainability [21].

A 'family' of scenarios is constituted based on the same storyline. IPCC has modeled a variety of scenarios under A1, A2, B1, B2 families. A1 family has three scenario groups, characterizing alternative development of below mentioned energy technologies with varying fuel mix: (i) A1F1 (fossil fuel intensive), (ii) A1B (balanced contribution of fossil and non-fossil fuels), and (iii) A1T (predominantly non-fossil fuel). All the other families have only one scenario group. All scenario groups are considered equally sound with no assigned probabilities of occurrence [21]. In recent report from IPCC [22], the scenarios have been changed slightly differently but broadly comparable to the scenarios in [2]. Consequently, the scenarios in [2] are employed in this study.

Since, IPCC reports provide limited information about the climate change in Australia, particularly in terms of regional projections; the CSIRO and the Bureau of Meteorology (BOM) have developed climate change projections for Australia as presented in [23], and [24] for the year 2007 and 2014 respectively. It is based on the outcomes of international climate change research along with the concluding remarks highlighted in the fourth assessment report of IPCC.

\section{Climate Change in the Context of Australia}

CSIRO has used probability distribution function (PDF) as an indicator for identifying the effect of global mean warming on Australia and applied 'pattern scaling' approach with the assumption of proportional changes in regional climate variables against the global warming [23]. Using 1980-1999 as the baseline years for examining the regional projections, local changes in climatic conditions have been regressed against the global warming; and from the slope of the regression, the mean local change per degree of global warming has been determined. CSIRO has projected the effect of climate change on numerous weather variables for the years 2030s, 2050s and 2070s; however, projection for individual year may vary distinctly. The impact of climate change in Australian context varies significantly from one demographic region to another. 


\section{A. Temperature}

Temperature in Australia has been rising by about $1{ }^{\circ} \mathrm{C}$ with an increase in the frequency of heat waves and a decrease in the number of frosts and cold days since middle of $20^{\text {th }}$ century [25]. Other climatic variables such as rainfall and wind have been also changed in different regions of Australia.

Fourth assessment report, prepared by IPCC, concludes that the global temperature warming is inevitable due to associated human processes and ongoing change will continue in future [2]. It is noted that the best estimate of the global mean warming for year 2030 does not vary significantly among the emission scenarios. From the CSIRO estimation, it is found that the 'best estimate' of temperature in Australia differs in coastal and inland areas. The variation of temperature in coastal areas is between $0.7^{\circ} \mathrm{C}$ to $0.9^{\circ} \mathrm{C}$, while the temperature variation for inland areas is between $1^{\circ} \mathrm{C}$ to $1.2^{\circ} \mathrm{C}$ by 2030 . It is reported that in the late twenty first century, global warming will vary as per the future emission scenario described in [23]. By 2050, change in temperature in Australia will vary from around $0.8^{\circ} \mathrm{C}$ to $1.8^{\circ} \mathrm{C}$ for $\mathrm{B} 1$ scenario and $1.5^{\circ} \mathrm{C}$ to $2.8^{\circ} \mathrm{C}$ for the $\mathrm{A} 1 \mathrm{~F} 1$ scenario [23]. $\mathrm{By}$ 2070 , the annual warming will vary from $1.0^{\circ} \mathrm{C}$ to $2.5^{\circ} \mathrm{C}$ for the $\mathrm{B} 1$ scenario to $2.2^{\circ} \mathrm{C}$ to $5.0^{\circ} \mathrm{C}$ for the $\mathrm{A} 1 \mathrm{~F} 1$ scenario [23].

\section{B. Other Climatic Variables}

Although temperature is one of the key variables among all the weather variables, and expected to change to a greater extend with changing climatic conditions, other weather variables like rainfall, evaporation, wind speed and relative humidity might get altered as well. The IPCC report [2] has concluded that the regional pattern of certain climatic variables such as precipitation will generally decrease in the subtropics. Contrarily, evaporation may increase in future. Other climatic variables will also get altered and the extent of these changes may vary from one region to another.

\section{Projected Climate Change for the City of Sydney, Australia}

The technical report prepared by CSIRO, for the Australian Bureau of Meteorology and Australian Greenhouse Office, [23] has summarized the impact of climate change on some of the major cities in Australia for the years 2030 and 2070 . To project the impact of climate change on Sydney in 2030, A1B SRES scenario (Special Report on Emission Scenario) developed by IPCC has been adopted. As discussed earlier, A1B belongs to A1 family characterized by a balance between fossil fuel and non-fossil fuel based technology. The projection of climatic variables for Sydney in year 2070 has been carried out for B1 and A1F1 scenarios. Table I shows the CSIRO forecast (for the best estimate) of climate variables for Sydney considering 1980-1999 as the baseline years [23]. From this table, it has been observed that average values of temperature, solar radiation and evaporation will increase whereas average amount of rainfall will decrease for Sydney in the future years. Relative humidity might increase or decrease depending on the emission scenario. However, wind speed will remain almost unchanged in future.

\section{Proposed Analytical Approach for Analyzing Demand Sensitivity to Weather Variables}

Climatic condition comprises of different weather variables. Change in each of these variables might impact electricity demand. It is therefore necessary to investigate the dependency of the weather variables such as temperature, rainfall, solar exposure, wind speed and humidity on electricity demand. Regression analysis has been performed using the historical data to investigate the dependency of different weather variables on demand. Such analysis often deals with huge data and therefore it is important to exclude non-significant variables.

\section{A. Weather Variables}

While the weather variables are continuously changing, there might be some hidden relationship among these variables. Temperature is one of the key variables that controls atmospheric condition and it could be plausibly apparent that all weather variables on the Earth will, more or less, be affected by temperature [25]. Earth surface gets heated from the solar energy and thus, temperature and solar exposure are expected to have close relationship. Temperature causes evaporation that leads to humidity. Again, air pressure and wind speed are also controlled by the variation in temperature. This interdependency between weather variables could be very complex. In all, temperature is the most dominant climatic variable and has a higher impact on electricity demand [26].

Identifying the correlation among different variables is best measure to gauge their interdependency. Pearson's correlation technique is commonly used for this purpose, which generates correlation coefficient between -1.0 and +1.0 to interpret the degree of correlation between different variables [27]. While +1.0 indicates a perfect positive correlation;-1.0 signifies a perfect inverse correlation; and 0 means no correlation. Commonly used formula for Pearson's correlation is given in (1).

$$
r_{x y}=\frac{n \sum x y-\sum x \sum y}{\sqrt{\left[n \sum x^{2}-\left(\sum x\right)^{2}\right]\left[n \sum y^{2}-\left(\sum y\right)^{2}\right]}}
$$

Where, $r_{x y}$ is the correlation index between variables $x$ and $y$, and $n$ is the total number of data points. When the numerator and 
denominator in (1) are divided by $n^{2}$, the equation can be rewritten as below:

$$
r_{x y}=\frac{M_{x y}-M_{x} M_{y}}{\sqrt{\left[M_{x}{ }^{2}-M_{x^{2}}\right]\left[M_{y}{ }^{2}-M_{y^{2}}\right]}}
$$

Where,

$$
\begin{aligned}
& M_{x}=\frac{1}{\mathrm{n}} \sum x, M_{y}=\frac{1}{n} \sum y, \mathrm{M}_{x y}=\frac{1}{n} \sum x y \\
& M_{x}{ }^{2}=\frac{1}{\mathrm{n}^{2}}\left(\sum x\right)^{2}, M_{y}{ }^{2}=\frac{1}{n}\left(\sum y\right)^{2}
\end{aligned}
$$

It is noted that (2) can be expressed as the standard deviation of variable $x$ and $y$. Thus, an alternative way to represent the above equation is given below:

$$
r_{x y}=\frac{\sum x y /(n-1)}{s d_{x} . s d_{y}}
$$

Where $s d_{x}$ and $s d_{y}$ are the standard deviations of variable $x$ and $y$ respectively and can be expressed as,

$$
s d_{x}=\sqrt{\frac{\sum x^{2}}{(n-1)}} \quad \text { and } \quad s d_{y}=\sqrt{\frac{\sum y^{2}}{(n-1)}}
$$

In this paper, Pearson's correlation coefficients are derived to investigate the correlation between temperature and other climatic variables.

\section{B. Balance Point Temperature}

Balance point temperature is a threshold temperature, which is frequently used in degree days' calculation. The per capita electricity demand is minimum at this point. Since this point is neither too cold nor too hot, electricity requirement for cooling and heating purposes is least at this temperature. A common practice in the literature is to consider $65^{\circ} \mathrm{F}\left(18.4^{\circ} \mathrm{C}\right)$ as a balance point temperature [4]. However, the value often varies in different regions due to geographical configurations. In the proposed study, balance point temperature for Sydney, Australia has been investigated based on per capita demand and temperature. If demand is projected against temperature on a scatter plot, ideally a ' $\mathrm{V}$ ' shaped trend curve [9] can be observed as shown in Fig. 1.

This trend curve can be obtained by drawing a bisectional straight line through the points in such a way that the associated least square error is at its minimum. The left portion of the ' $\mathrm{V}$ ' curve with negative slope corresponds to the heating requirement and the right portion of the curve with positive slope corresponds to cooling requirement. The common intersection of both the lines represents theoretical balance point temperature. The same methodology has been used in this paper to investigate balanced point temperature for Sydney.

\section{Degree Days}

Degree days represent the extent by which temperatures vary from balance point. According to the law of thermodynamics, if a substance weighing $w$ and having specific heat capacity of $S$ requires change in temperature of $\Delta \theta$, then the requisite energy $Q$ can be expressed by the following formula.

$$
Q=w S \Delta \theta
$$

This indicates that the energy required for a certain change in temperature is proportional to the temperature difference. Therefore, degree days are linearly related to the energy required for heating and cooling purposes. It is noted that the sensitivity of cooling and heating requirements may differ due to variabilities in the usage pattern by the customers and efficiency of heating and cooling load [26]. As a consequence, degree days can be depicted in the form of two separate variables which are CDD and HDD [26]. Furthermore, it is noted from [28] that these variables should be treated differently in the regression analysis by allocating separate coefficients to each variable. While CDD refers to the extent of cooling required due to temperature being higher than the reference temperature, HDD represents the extent of heating required due to the temperature being lower than the reference temperature. CDD and HDD can be calculated using (5) and (6) respectively [9].

$$
\begin{aligned}
& C D D=\frac{1}{n} \sum_{i=1}^{m} \sum_{j=1}^{n}\left(T-T_{b}\right) u \\
& H D D=\frac{1}{n} \sum_{i=1}^{m} \sum_{j=1}^{n}\left(T_{b}-T\right) u
\end{aligned}
$$

Where, $m$ is the number of days in a year, $n$ is the number of temperature data samples considered in a day, $T$ is the temperature at the $n^{\text {th }}$ hour of the $m^{\text {th }}$ day, $T_{b}$ is the balance point temperature, and $u$ is the unit function. 
The value of $u$ could be either 1 or 0 . In case of CDD, if the value of temperature difference, $\left(T-T_{b}\right)$ is positive, then the value of unit function is 1 ; otherwise it is 0 . Similarly, in case of HDD if $\left(T_{b}-T\right)$ is positive then the value of unit function is 1 ; otherwise it is 0 . Since half hourly data have been used, $n$ is 48 in this study. The value of $m$ is either 365 or 366 depending on whether the year under consideration is a leap year or not. In this paper, balance point temperature for Sydney has been estimated using historical temperature data.

To calculate future CDD and HDD, it has been assumed that all the temperature values in the base year will shift upwards to a value equal to the expected temperature change in future. The sample data used in this paper contains 48 data points for temperature in a single day. This leads to 17,520 temperature data in the base year. According to the assumption, all 17,520 points of the base year will be shifted upwards by $\Delta T$. If $T_{b}$ is the balance point temperature as given in Fig. 2, then five cases might occur. The point with temperature $T_{1}$, which lies between $T_{b}$ and $\left(T_{b}-\Delta T\right)$ will cross the $T_{b}$ line and thus will have a temperature difference of $\left(T_{1}+\Delta T-T_{b}\right)$ from the reference temperature, $T_{b}$. Thus, it will increment CDD calculation by a value of $\left(T_{1}+\Delta T\right.$ $\left.T_{b}\right) / 48$. The point with temperature $T_{2}$ will fall between $T_{b}$ and $\left(T_{b}-\Delta T\right)$ in the future and therefore will not affect CDD but will cause HDD to decrease by $\Delta T / 48$. The point with temperature $T_{3}\left(=T_{b}-\Delta T\right)$ will overlap $T_{b}$ and will not affect CDD; but, it will cause HDD to decrease by $\Delta T / 48 . T_{4}$ and $T_{5}$ will update the CDD value by $\Delta T / 48$ but they will not alter HDD. Thus, knowing the change in temperature $\Delta T$ for future years, based on the projections of CSIRO, change in future CDD and HDD for Sydney can be estimated.

\section{Multiple Regression Analysis}

The purpose of carrying out regression analysis is to examine the relative importance of different variables. Regression analysis helps to establish the relationship between independent and dependent variables and the extent of their dependency. In this study, multiple linear regression analysis is selected to express demand dependency in terms of linear combination of different weather variables. In linear regression model, the dependent variables are expressed in terms of independent variables and coefficients. The regression equation for electricity demand can be written as,

$$
D=\alpha+\sum_{i}^{n} c_{i} x_{i}+\varepsilon
$$

Where, $D$ is the aggregated per capita demand over a year expressed in MW, $\alpha$ is a constant term, $x_{i}$ is the weather variables, $c_{i}$ is the coefficients of the variables and ' $\varepsilon$ ' is the error term.

It is important to find the useful weather variables for climate induced demand calculation. The coefficients of these variables will be used along with the climate data for Sydney, projected by CSIRO, to estimate the change in per capita demand in the upcoming years. Fig. 3 shows conceptual framework of correlation among different weather variables and regression analysis to derive electricity demand. Temperature causes evaporation, humidity and air pressure. Thus there might be a correlation between temperature and three weather variables. Again, humidity can impact rainfall and air pressure can impact wind speed. Finally all the weather variables may contribute to the influence on electricity demand.

The important weather variables are temperature (represented in terms of degree days - DDs), wind speed ( $x_{w s}$ ), air pressure $\left(x_{a p}\right)$, rainfall $\left(x_{r f}\right)$, humidity $\left(x_{h d}\right)$ and evaporation $\left(x_{e v}\right)$. With these variables the regression equation can be expressed as,

$D=\alpha+c_{1} \cdot D D s+c_{2} \cdot x_{w s}+c_{3} \cdot x_{a p}+c_{4} \cdot x_{r f}+c_{5} \cdot x_{h d}+c_{6} \cdot x_{e v}+\varepsilon$

The backward elimination regression method has been adopted in this analysis. It starts with all the variables and then excludes the least significant variables from the model one by one. Using the backward elimination process, degree days including CDD and HDD are employed noting that either of the variables will be excluded. The sig value [29] can be employed to help determine the significant variables. In this analysis, the probability criterion to remove a variable from the model has been set as $\mathrm{F} \geq 0.05$ [30]. Therefore, after the first regression analysis, the least significant variable, for which 'sig' value is maximum is removed from the model and a second model is formed after excluding this variable. Subsequently, second regression analysis is conducted and another variable is eliminated if it is found to be insignificant. This process continues until all the variables in the model have 'sig' value $\leq 0.05$. Some significant variables may be highly correlated with each other, which may result into high 'sig' value due to the sharing of their significance level among themselves [31]. Correlation analysis can identify the variables that are susceptible to this criterion. In the proposed study, this particular aspect has been accounted during variable elimination process in the multiple linear regression analysis.

\section{Results and Discussions}

Historical electricity demand data for the period of 1999 to 2010 comprising demand from all sectors have been procured from Australian Energy Market Operator (AEMO) [32] and used in this study. Per capita demand for each year has been calculated from the historical values of total population in the corresponding year, obtained from Australian Bureau of Statistics [33]. In this 
study, per capita electricity demand is used instead of total demand to eliminate the impact of population growth over the years. Historical data of the weather variables for Sydney airport station, collected from the Bureau of Meteorology, have been used in this analysis.

\section{A. Selection of Weather Variables}

To investigate the correlation between temperature and other weather variables, Pearson's correlation coefficients, as discus sed earlier, have been evaluated using SPSS tool. In this paper, monthly average data obtained from [34] have been used to find out the correlation between different weather variables. Higher value of correlation coefficient indicates possible existence of 'multicolinearity' in the regression analysis, which signifies interdependency between two significantly impacting variables. Fig. 4 shows correlation between temperature and other weather variables. From Fig. 4, it is observed that rainfall, wind speed and humidity have inconsistently correlated with temperature. However, evaporation shows high correlation with temperature.

\section{B. Historical Pattern of Total Electricity Demand and Weather Variables}

Historical yearly average per capita electricity demand have been plotted against weather variables. If linearity is found between the demand and a single weather variable, then simple linear regression is sufficient instead of multiple regression analysis. Based on the historical data available from 1999 to 2010 for electricity demand, per capita yearly electricity demand with respect to weather variables has been depicted in Fig. 5. The results obtained using bivariate correlation highlighting relations between different variables are analyzed. It has been observed that none of the variables are linearly related with the demand. However, CDD, HDD, evaporation and wind speed have a potential to be positively correlated with electricity demand; on the other hand, rainfall and humidity seem to be negatively related. Table II presents the Pearson's correlation matrix, where interrelationships among different variables can be observed in terms of different correlation coefficients. From Table II, it is seen that more than one variable are required to establish the relationship with the electricity demand. Multiple regression analysis will help to relate only significant variables with the demand and exclude non-significant variables. It will also help to quantify the extent of the influence of individual variables on the demand pattern.

\section{Identification of Balance Point Temperature}

To identify a reference temperature point for Sydney, the per capita demands with half-hourly resolution in different years have been plotted against temperature as in Fig.6. It can be seen from this figure that per capita demand and temperature may have quadratic relationship. The associated quadratic equation has been differentiated to find the minima and to figure out threshold level for individual year. It was expected that threshold level for individual years would be the same but in reality they are all different. Year-wise analysis shows threshold level of balance point temperature varies from $12.6^{\circ} \mathrm{C}$ to $16.9^{\circ} \mathrm{C}$ in the past years (1999-2010). Historical demand and temperature data have been projected to generate trend-lines of individual years based on least-square error. It is observed that minima of the trend-lines for individual years vary. Therefore, a single trend-line has been generated utilizing all the available demand data for the period of 12 years (1999 to 2010) and presented in Fig. 6 [9]. The equation for this single trend-line has been derived and shown in the figure. Based on the single trend-line, balance point temperature for Sydney has been calculated and found to be $14.3^{\circ} \mathrm{C}$. This balance point temperature value is different from the commonly used value, and it is acceptable since this value is determined based on the actual relationship between demand and temperature [7].

\section{Multiple Regression Analysis}

Electricity demand sensitivity to the model variables is examined in this section. Initially, degree days (including CDD and HDD), rainfall, wind speed, humidity, and evaporation have been included in the regression model. Using SPSS statistical tool, regression analysis has been performed and the associated coefficients have been investigated. The 'sig' value of a variable less than 0.05 implies significant effect of the related variable on the demand. However, due to possible 'multicolinearity' effect, some values may become insignificant although they have significant role in evaluating the per capita demand. Since back elimination method has been adopted, first regression analysis has been performed for all the weather variables. It shows that HDD is least significant with the significance level of 0.721 . In the next stage, second regression has been carried out excluding HDD from the model. This time, it has been observed that rainfall is insignificant having the significant level of 0.819 . Therefore, rainfall is excluded in the third regression process, and likewise humidity is excluded in the fourth regression process. Although 'sig' level of evaporation has been appeared to be 0.055 in the fourth regression analysis, this has been retained in the final model due to 'multicolinearity' effect discussed earlier. Therefore, final model includes CDD, wind speed and evaporation. The results obtained in different stages of the multiple regression analysis by back elimination process are tabulated in Table III. The value of $\mathrm{R}^{2}$ indicates how well the dependent variables can be expressed by the independent variables. The final model excluding all nonsignificant variables gives $\mathrm{R}^{2}$ value of $81.6 \%$. Therefore, it can be concluded that the model fits well with the historical data and capable to estimate future demand. Fig. 7 shows modeled demand and historical demand values to depict how well the proposed backward elimination based multiple regression model can predict the electricity demand. 


\section{E. Climate Change Demand Response}

From the regression analysis, it has been found that CDD, wind speed, evaporation and humidity are significant variables for estimating climate induced future electricity demand for Sydney. From the CSIRO projection about future temperature changes in Sydney in 2030 and 2070, expected changes in CDD in the corresponding years have been estimated. Change in wind speed has been estimated as nil by CSIRO and therefore will not have any impact on Sydney's future electricity demand. The change in evaporation and the change in humidity for the upcoming years have been also calculated using CSIRO data. Table IV shows expected change in different weather variables in year 2030 and 2070.

From the coefficients obtained in multiple regression analysis along with the predicted change in future variables (given in Table IV), change in future per capita demand has been calculated for 2030 and 2070. The results included in Table V shows that the per capita demand will largely be affected due to climate change. Average per capita demand will rise approximately $6 \%$ in year 2030. However, per capita demand in the later years will vary based on the future emission scenarios. It is noted that the per capita demand will rise $11.2 \%$ for B1 and $21.6 \%$ for A1F1 scenario in the year 2070 .

It is worth noting that only climatic variables are investigated in this study, with the assumption of neglecting the impact of changes in energy efficiency and associated variations in electricity demand.

\section{Conclusion}

This paper has analyzed the impact of climatic variables on load demand for the city of Sydney, Australia. The correlation analysis and multiple regression analysis have successfully identified significant weather variables that have strong influence on the electricity demand of Sydney. The study has found that HDD may not have significant impact on the per capita demand in Sydney and it should be removed from the regression equation. However, due to average rise of temperature, more cooling and consequently, more electricity consumption has been expected in future. Based on the regression analysis, it is observed that change in future CDD due to temperature variation, wind speed and evaporation affect the future load demand.

With the aid from future projection of climate change in different scenarios available from IPCC and CSIRO the future load demand has been predicted for the city of Sydney, Australia considering the impact of climatic variables and their degree of sensitivity to the demand. The results obtained in this paper have demonstrated the degree of vulnerability of the electricity load demand to climate change for the city of Sydney and found that average load will increase in the future as illustrated using the change of climatic variables in different scenarios. More specifically, the study has found that the demand would increase by $6 \%$ by the year 2030, and from $11.2 \%$ to $21.6 \%$ depending on different scenarios by the year 2070 .

The proposed study did not account for energy efficiency and related changes in electricity demand during the forecasting period. In addition, the results of this study have been obtained based on the dataset (covering years 1999 to 2009) acquired from the city of Sydney, Australia. The relationship between demand and climatic variables would be different for a dataset corresponding to some other location. In such case, the proposed methodology can be used to establish a forecasting model but the significant inputs and coefficients of the model may change accordingly.

\section{References}

[1] R. L. McGinnis and M. Elimelech, "Global Challenges in Energy and Water Supply: The Promise of Engineered Osmosis," Environmental Science \& Technology, vol. 42, pp. 8625-8629, 2008/12/01 2008.

[2] R. K. Pachauri and A. R. (eds), "Climate change 2007: Synthesis report - Contribution of Working Groups I, II and III to the Fourth Assessment Report of the Intergovernmental Panel on Climate Change," Geneva, Switzerland2007.

[3] D. J. Sailor, "Relating residential and commercial sector electricity loads to climate-evaluating state level sensitivities and vulnerabilities," Energy, vol. 26, pp. 645-657, 2001.

[4] S. M. Howden and S. Crimp, "Effect of climate and climate change on electricity demand in Australia," 2001.

[5] M. J. Thatcher, "Modelling changes to electricity demand load duration curves as a consequence of predicted climate change for Australia," Energy, vol. 32, pp. 1647-1659, 9// 2007.

[6] C. Gerk Hing and L. Tek Tjing, "The impact of climate change on New Zealand's electricity demand," in Probabilistic Methods Applied to Power Systems (PMAPS), 2010 IEEE 11th International Conference on, 2010, pp. 808-813.

[7] A. Amato, M. Ruth, P. Kirshen, and J. Horwitz, "Regional Energy Demand Responses To Climate Change: Methodology And Application To The Commonwealth Of Massachusetts," Climatic Change, vol. 71, pp. 175-201, 2005/07/01 2005.

[8] T. Wilson, L. William, J. Smith, and R. M. (eds), "Global climate change and california: Potential implications for ecosystem health and the economy," California Energy Commision, California2003.

[9] T. Ahmed, K. M. Muttaqi, and A. P. Agalgaonkar, "Climate change impacts on electricity demand in the State of New South Wales, Australia," Applied Energy, vol. 98, pp. 376-383, 2012. 
[10] M. Hekkenberg, H. C. Moll, and A. J. M. S. Uiterkamp, "Dynamic temperature dependence patterns in future energy demand models in the context of climate change," Energy, vol. 34, pp. 1797-1806, 2009.

[11] P. Xu, Y. J. Huang, N. Miller, N. Schlegel, and P. Shen, "Impacts of climate change on building heating and cooling energy patterns in California," Energy, vol. 44, pp. 792-804, 8// 2012.

[12] J. A. Dirks, W. J. Gorrissen, J. H. Hathaway, D. C. Skorski, M. J. Scott, T. C. Pulsipher, M. Huang, Y. Liu, and J. S. Rice, "Impacts of climate change on energy consumption and peak demand in buildings: A detailed regional approach," Energy, vol. 79, pp. 20-32, 1/1/ 2015.

[13] T. Zachariadis and P. Hadjinicolaou, "The effect of climate change on electricity needs - A case study from Mediterranean Europe," Energy, vol. 76, pp. 899-910, 11/1/ 2014.

[14] S. Jovanović, S. Savić, M. Bojić, Z. Djordjević, and D. Nikolić, "The impact of the mean daily air temperature change on electricity consumption," Energy.

[15] D. H. Vu, K. M. Muttaqi, and A. P. Agalgaonkar, "Assessing the influence of climatic variables on electricity demand," in PES General Meeting | Conference \& Exposition, 2014 IEEE, 2014, pp. 1-5.

[16] D. H. Vu, K. M. Muttaqi, and A. P. Agalgaonkar, "A variance inflation factor and backward elimination based robust regression model for forecasting monthly electricity demand using climatic variables," Applied Energy, vol. 140, pp. 385-394, 2015.

[17] K. G. Boroojeni, M. H. Amini, S. Bahrami, S. S. Iyengar, A. I. Sarwat, and O. Karabasoglu, "A novel multi-time-scale modeling for electric power demand forecasting: From short-term to medium-term horizon," Electric Power Systems Research, vol. 142, pp. 58-73, 1// 2017.

[18] Z. Shao, F. Chao, S.-L. Yang, and K.-L. Zhou, "A review of the decomposition methodology for extracting and identifying the fluctuation characteristics in electricity demand forecasting," Renewable and Sustainable Energy Reviews.

[19] D. H. Vu, K. M. Muttaqi, and A. P. Agalgaonkar, "Combinatorial approach using wavelet analysis and artificial neural network for short-term load forecasting," in Power Engineering Conference (AUPEC), 2014 Australasian Universities, 2014, pp. 1-6.

[20] P. H. Whetton, K. L. Mclnnes, R. N. Jones, K. J. Henness, R. Suppiah, C. M. Page, J. Bathols, and P. J. Durack, "Climate change projections for Australia for impact assessment and policy application: a review," CSIRO Technical paper, 2005.

[21] N. Nakicenovic and e. R. Swart, "Emission scenarios, A special report of working group III of the intergovernmental panel on climate change," 2000.

[22] R. K. Pachaur and L. A. M. (eds), "Climate Change 2014: Synthesis Report. Contribution of Working Groups I, II and III to the Fifth Assessment Report of the Intergovernmental Panel on Climate Change ", Geneva, Switzerland2014.

[23] K. Pearce, P. Holper, M. Hopkins, W. Bouma, P. Whetton, K. Hennessy, and S. Power, "Climate change in Australia: Technical Report," CSIRO and the Australian Bureau of Meteorology2007.

[24] M. Ekström, C. Gerbing, M. Grose, J. Bhend, L. Webb, and J. Risbey, "Climate change in Australia: Technical Report," CSIRO and the Australian Bureau of Meteorology2015.

[25] L. Guan, J. Yang, and J. M. Bell, "Cross-correlations between weather variables in Australia," Building and Environment, vol. 42, pp. 1054-1070, 2007.

[26] C.-L. Hor, S. J. Watson, and S. Majithia, "Analyzing the impact of weather variables on monthly electricity demand," Power Systems, IEEE Transactions on, vol. 20, pp. 2078-2085, 2005.

[27] J. Cohen, P. Cohen, S. G. West, and L. S. Aiken, applied multiple regression correlation analysis for the behavioral sciences. Mahwah, New Jersey: LAWRENCE ERLBAUM ASSOCIATES, PUBLISHERS, 2003.

[28] I. M. Trotter, T. F. Bolkesjø, J. G. Féres, and L. Hollanda, "Climate change and electricity demand in Brazil: A stochastic approach," Energy, vol. 102, pp. 596-604, 2016/05/01/ 2016.

[29] L. Demortier, "P Values: What They Are and How to Use Them," The Rockefeller University2007.

[30] D. C. Montgomery and G. C. Runger, Applied statistics and probability for engineers. United States of America: John Wiley \& Sons, Inc, 2003.

[31] J. D. Curto and J. C. Pinto, "New Multicollinearity Indicators in Linear Regression Models," International Statistical Review, vol. 75, pp. 114-121, 2007.

[32] Australian Energy Market Operator Available: http://www.aemo.com.au.

[33] Australian Bureau of Statistics [cited on 15 Apr 2011]. Available: http://www.abs.gov.au.

[34] Bureau of Meteorology, Australian government. [cited on 4 May 2012] ([cited on 4 May 2012] ed.). Available: http://www.bom.gov.au/climate/change 
Table I: Annualized climate change projection for Sydney based on the probabilistic method

\begin{tabular}{|l|r|r|r|}
\hline Variable & $\mathbf{2 0 3 0}$ & $\mathbf{2 0 7 0}$ & $\mathbf{2 0 7 0}$ \\
& A1B & $\mathbf{B 1}$ & A1F1 \\
\hline Temperature $\left({ }^{\circ} \mathrm{C}\right)$ & 0.9 & 1.6 & 3.0 \\
\hline Rainfall $(\%)$ & -3 & -4 & -8 \\
\hline Potential Evaporation (\%) & +3 & +5 & +9 \\
\hline Wind Speed (\%) & 0 & 0 & -1 \\
\hline Relative Humidity (\%) & -0.4 & -0.6 & -1.2 \\
\hline Solar Radiation (\%) & +0.3 & +0.5 & +0.9 \\
\hline
\end{tabular}

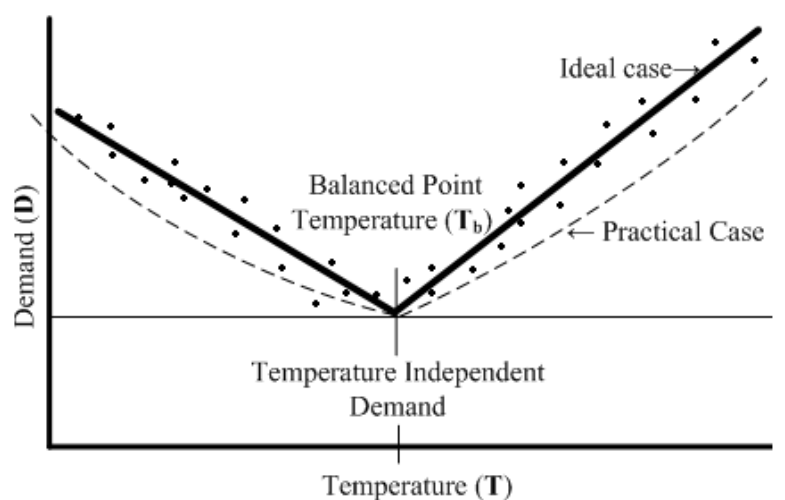

Fig. 1. Balance point temperature.

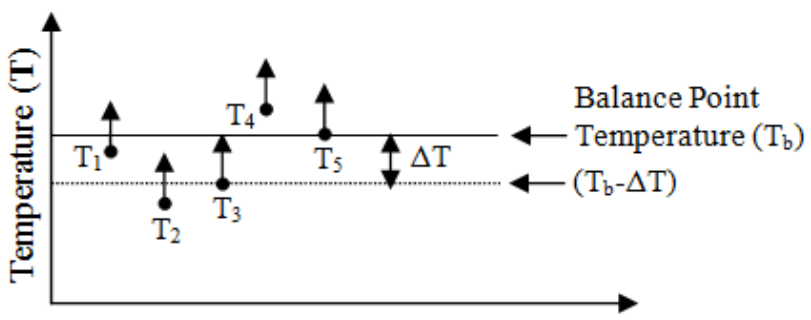

Fig. 2. Estimation of future CDD and HDD. 


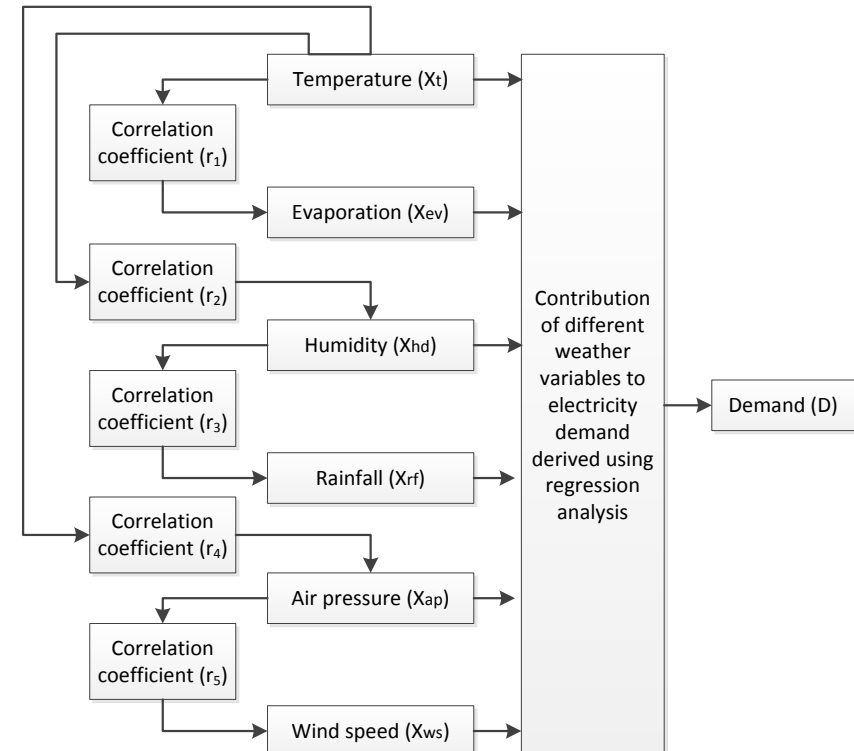

Fig. 3. Conceptual framework to derive electricity demand using regression analysis.

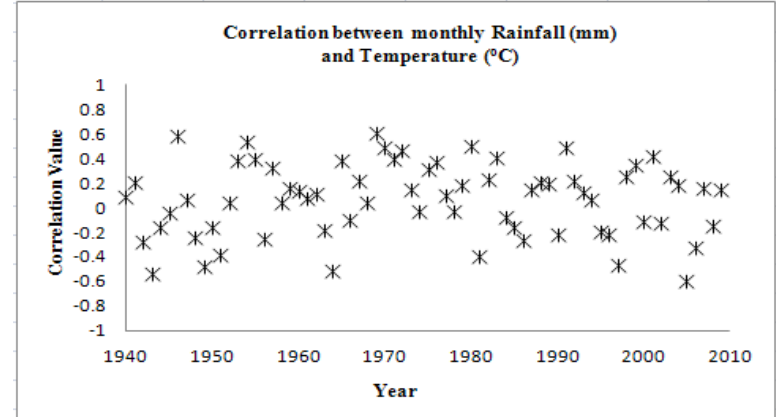

(a)

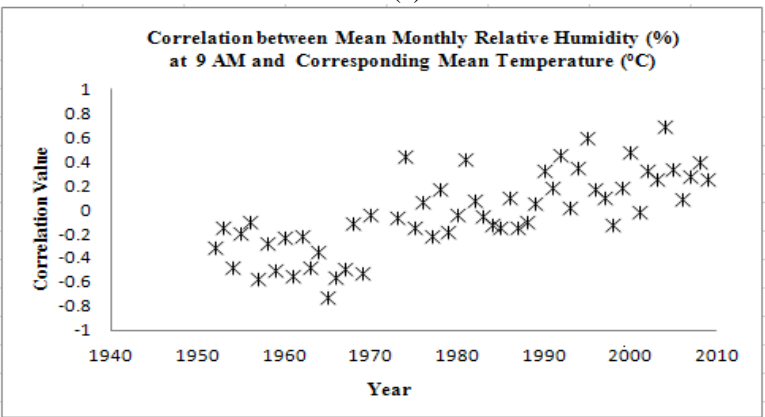

(c)

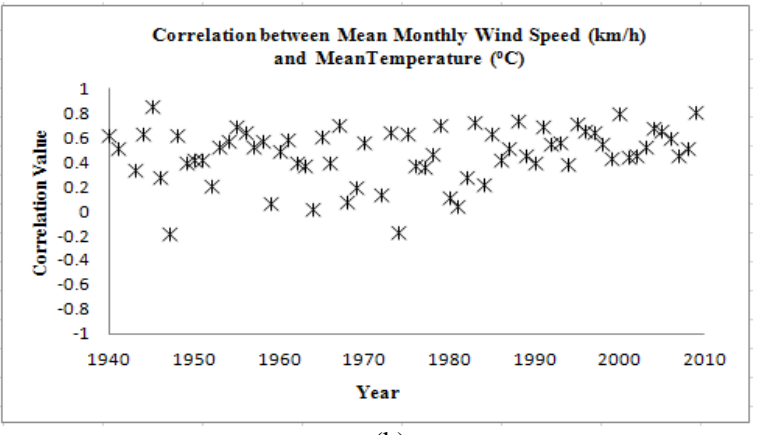

(b)

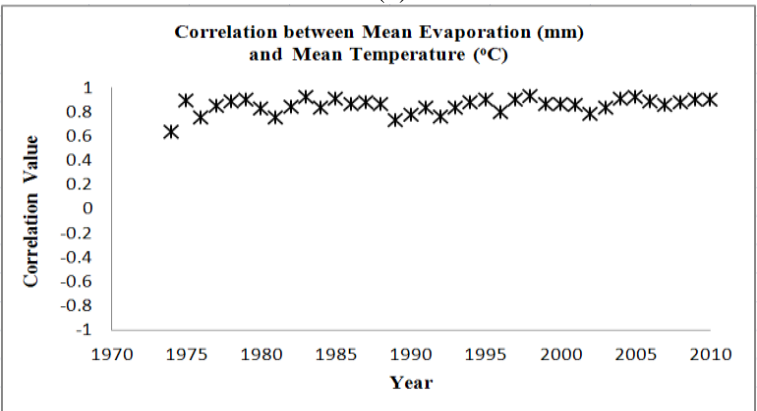

(d)

Fig. 4. Correlation between temperature and other weather variables.

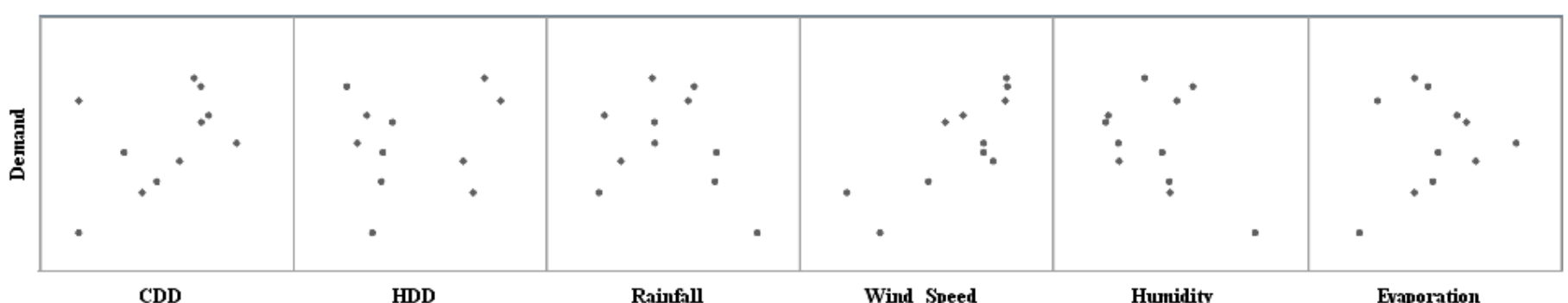

Fig. 5. Historical pattern of per capita yearly electricity demand and weather variables. 
Table II: Pearson's correlation matrix

\begin{tabular}{|c|c|c|c|c|c|c|c|}
\hline & Demand & CDD & HDD & $\begin{array}{c}\text { Rain- } \\
\text { fall }\end{array}$ & $\begin{array}{c}\text { Evapo- } \\
\text { ration }\end{array}$ & $\begin{array}{c}\text { Humi- } \\
\text { dity }\end{array}$ & $\begin{array}{l}\text { Wind } \\
\text { speed }\end{array}$ \\
\hline Demand & 1 & .459 & .154 & -.281 & .199 & -.454 & .799 \\
\hline CDD & .459 & 1 & -.342 & -.553 & .833 & -.733 & .340 \\
\hline HDD & .154 & -.342 & 1 & -.356 & -.332 & -.067 & .045 \\
\hline Rainfall & -.281 & -.553 & -.356 & 1 & -.498 & .731 & -.004 \\
\hline Evaporation & .199 & .833 & -.332 & -.498 & 1 & -.823 & .314 \\
\hline Humidity & -.454 & -.733 & -.067 & .731 & -.823 & 1 & -.381 \\
\hline Wind Speed & .799 & .340 & .045 & -.004 & .314 & -.381 & 1 \\
\hline
\end{tabular}

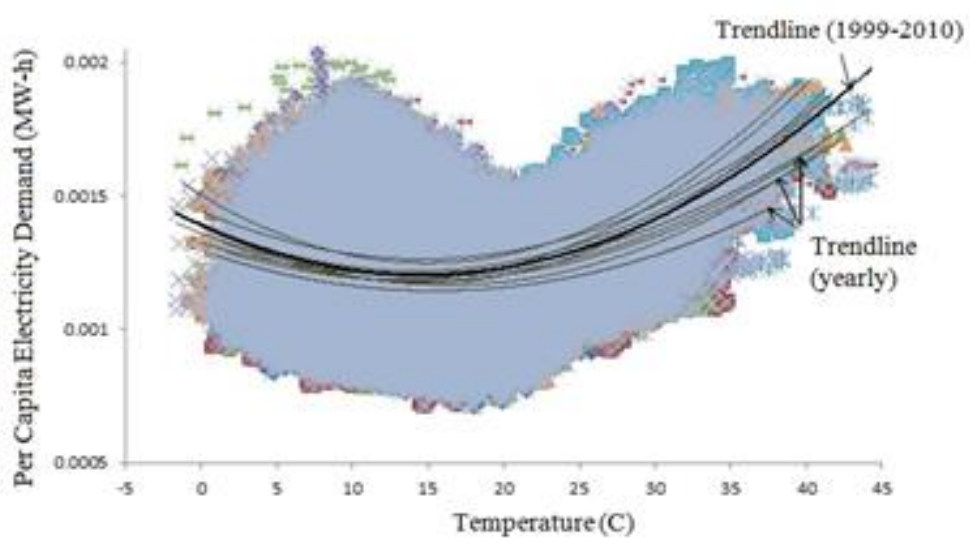

Fig. 6. Relationship between per capita electricity load demand and temperature in past 12 years.

Table III: Model summary and significance level derived using backward elimination based regression analysis

\begin{tabular}{|c|c|c|c|c|c|c|c|c|c|c|}
\hline \multirow{2}{*}{$\begin{array}{c}\text { Model } \\
\text { No. }\end{array}$} & \multicolumn{3}{|c|}{ Model Summary } & \multicolumn{7}{|c|}{ Significance level of Predictors (Sig. value in the regression analyses) } \\
\hline & $\mathbf{R}$ & $\mathbf{R}^{2}$ & Adjusted $\mathbf{R}^{2}$ & (Constant) & CDD & Evaporation & Wind speed & Humidity & Rainfall & HDD \\
\hline 1 & .952 & .907 & .768 & .119 & .162 & .055 & .025 & .293 & .704 & .721 \\
\hline 2 & .951 & .904 & .808 & .073 & .055 & .031 & .010 & .259 & .819 & Removed \\
\hline 3 & .950 & .903 & .838 & .015 & .025 & .010 & .003 & .061 & Removed & Removed \\
\hline 4 & .904 & .816 & .738 & .013 & .036 & .055 & .003 & Removed & Removed & Removed \\
\hline
\end{tabular}

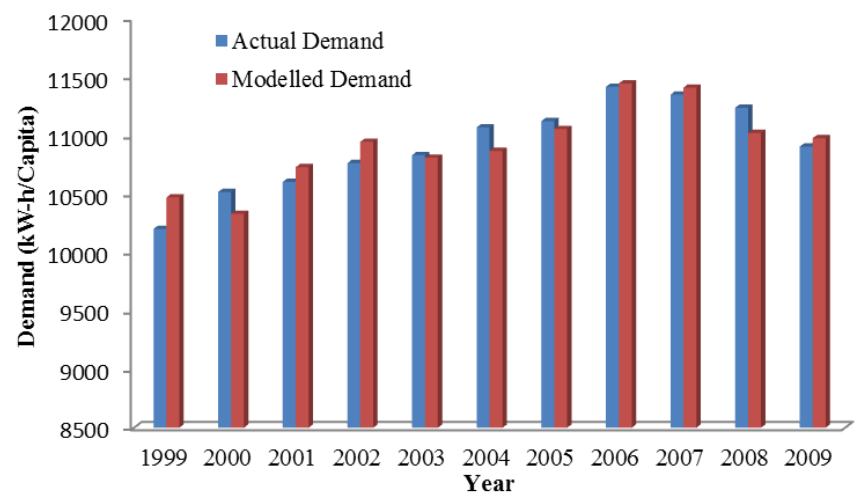

Fig. 7. Historical and modelled load demand. 
Table IV: Expected change of regression variables in future

\begin{tabular}{|c|c|c|c|}
\hline Variables & $\begin{array}{c}\mathbf{2 0 3 0} \\
\text { A1B }\end{array}$ & $\begin{array}{c}\mathbf{2 0 7 0} \\
\text { B1 }\end{array}$ & $\begin{array}{c}\mathbf{2 0 7 0} \\
\text { A1F1 }\end{array}$ \\
\hline Change in Temperature $\left({ }^{\circ} \mathrm{C}\right)$ & 0.9 & 1.6 & 3.0 \\
\hline Change in CDD & 265.2 & 482.5 & 938.9 \\
\hline Change in Wind Speed $(\mathrm{km} / \mathrm{h})$ & 0 & 0 & -81.9 \\
\hline Change in Evaporation $(\mathrm{mm})$ & 59.6 & 99.4 & 178.8 \\
\hline
\end{tabular}

Table V: Expected change in future load demand

\begin{tabular}{|c|c|c|}
\hline Year & Scenario & $\begin{array}{c}\text { \% Total change in load } \\
\text { demand }\end{array}$ \\
\hline 2030 & A1B & $6 \%$ \\
\hline 2070 & B1 & $11.2 \%$ \\
\hline 2070 & A1F1 & $21.6 \%$ \\
\hline
\end{tabular}

